\title{
Strong magnetoelectrolysis effect during electrochemical reaction monitored in situ by high-resolution NMR spectroscopy
}

\author{
Bruna Ferreira Gomes a, *, Pollyana Ferreira da Silva ${ }^{a}$, Carlos Manuel Silva Lobo a, \\ Maiara da Silva Santos ${ }^{b}$, Luiz Alberto Colnago ${ }^{c}$ \\ ${ }^{a}$ Universidade de São Paulo, Instituto de Química de São Carlos, São Carlos, SP, Brazil \\ ${ }^{\mathrm{b}}$ Universidade Federal de São Carlos, Derpartamento de Química, São Carlos, SP, Brazil \\ ${ }^{\mathrm{c}}$ Embrapa Instrumentação, São Carlos, SP, Brazil
}

\section{H I G H L I G H T S}

- The effect of the high magnetic field of NMR spectrometers on electrochemical reactions is evaluated.

- High resolution NMR is not a passive technique when coupled with in situ electrochemical experiments.

- The reaction kinetics change when subjected to a magnetic field.

- Previous papers have not taken this effect into consideration in their studies.

\section{A R T I C L E I N F O}

\section{Article history:}

Received 25 December 2016

Received in revised form

14 June 2017

Accepted 15 June 2017

Available online 22 June 2017

\section{Keywords:}

Magnetoelectrolysis

Electrochemistry-NMR

Diamagnetic molecules

Magnetic field

\section{G R A P H I C A L A B S T R A C T}

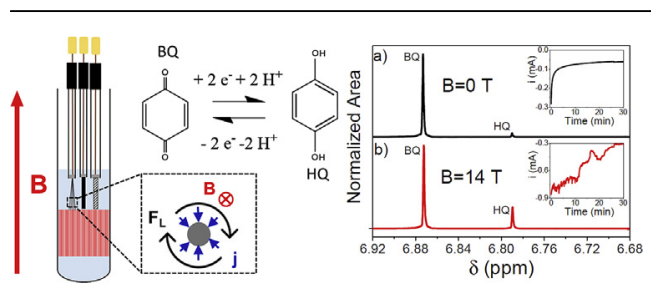

\begin{abstract}
A B S T R A C T
The strong effect of magnetic field on the electrochemical (EC) reduction of a diamagnetic species was monitored in situ in a $600 \mathrm{MHz}(14 \mathrm{~T})$ NMR spectrometer. Throughout EC-NMR experiments, the diamagnetic species is influenced by the Lorentz force (cross product of current density and magnetic field), which in turn acts on analyte transport and, as a result, enhances reaction rates. This phenomenon, known as magnetoelectrolysis, has not been considered in several in situ EC-NMR studies in solution, electron paramagnetic resonance (EC-EPR) spectroscopy, and magnetic resonance imaging (EC-MRI) involving the oxidation and reduction of organic compounds and lithium ion batteries. Recently, we have demonstrated the presence of this effect in the electroplating of a paramagnetic ion species by monitoring it in situ in a low-field $(0.23 \mathrm{~T}) \mathrm{NMR}$ spectrometer. In this report, a ca. five-fold enhancement in the electroreduction rate of benzoquinone was observed when the analyses were performed in situ in the NMR spectrometer. Therefore, this work has the objective of informing the scientific community that before every electrochemical reaction carried out in situ in NMR, EPR and MRI apparatuses, the influence of the magnetic field on the reactions must be evaluated, since it can alter the mechanism and kinetics of the reaction which, if not taken into account may lead to wrong interpretations of the data.
\end{abstract}

๑) 2017 Elsevier B.V. All rights reserved.

\footnotetext{
* Corresponding author.

E-mail address: bruna.fg.lobo@gmail.com (B. Ferreira Gomes).
}

\section{Introduction}

In situ studies of electrochemical reactions by Nuclear Magnetic Resonance (EC-NMR) and Electron Paramagnetic Resonance (ECEPR) spectroscopies as well as by Magnetic Resonance Imaging (ECMRI) have been used to determine reaction kinetics, mechanisms, 
and mass transport in real time [1-19]. Although these experiments have been performed in the presence of a magnetic field, $\mathbf{B}$, none of them has considered the magnetoelectrolysis phenomenon. Magnetoelectrolysis is the turbulence-inducing effect of the magnetic field on electrochemical reactions and is widely known [20-27]. Lorentz Force, $\mathbf{F}_{\mathbf{L}}$ (Eq. (1)), is the main force driving magnetoelectrolysis, which acts on the mass transport and is proportional to the cross product between magnetic field intensity (B) and current density (j).

$\mathbf{F}_{\mathbf{L}}=\mathbf{j} \times \mathbf{B}$

As demonstrated by Kelly in 1977, the magnetic field can alter processes controlled by mass transport or by charge-transfer. When the process is controlled by mass transport, the magnetic field can alter the thickness of the diffusion layer because it creates stirring on the solution, changing the kinetics on the reaction. However, when the reaction is controlled by charge-transfer, the magnetic field can alter the potential between the solution and the electrode and in some cases it can change the reaction mechanism [28].

It is worth pointing out that even when the magnetic field is oriented perpendicular to the electrode surface (parallel to $\mathbf{j}$ ) a resulting $\mathbf{F}_{\mathbf{L}}$ will still be present mainly due to the edge effects of the electrode surface and gas bubbles which locally distort the electric field (and thus the ionic flow) which creates a local resulting Lorentz force [22]. This secondary effect is known as micro magnetohydrodynamic effect (micro-MHD).

Recently we have demonstrated that the eletrodeposition of $\mathrm{Cu}^{2+}$ (a paramagnetic species) is enhanced when it is monitored using a low field (0.23 T) time domain NMR relaxometer [29,30]. In these works we also confirmed the presence of the micro MHD effect.

The active interference of the magnetic field of a high-resolution NMR spectrometer $(14 \mathrm{~T})$ on an electrochemical reaction of diamagnetic species has been analyzed in situ and is demonstrated in this article. The magnetic field of the NMR spectrometer increased the mass transport and, consequently, the reaction rate. Therefore, the electrochemical reaction was much faster than its ex situ counterpart. Furthermore, the magnetic field is capable of changing the reaction mechanism in certain systems, so it is very important to check what effect the magnetic field has on the reactions before using EC-NMR, EC-EPR or EC-MRI in order to ensure the correct interpretation of the data acquired through these studies.

We have used the $p$-benzoquinone (BQ) electroreduction to hydroquinone (HQ) as a reaction model to demonstrate the magnetoelectrolysis phenomenon because this reaction is often used to demonstrate the efficiency of the EC-NMR coupling $[9,2,31]$ and is also linked to pharmaceutical degradation reactions in biological systems [32]. It is worth noting that this phenomenon is also seen in other mass-transport limited systems [28,25,22], however, here we focus only on the reduction of $\mathrm{BQ}$ since we aim only to demonstrate the existence of the phenomenon during the EC-NMR coupling.

\section{Experimental}

\subsection{Chemicals and solutions}

p-benzoquinone (98\%, Sigma-Aldrich) was recrystallized from hot water $\left(\mathrm{T}=80{ }^{\circ} \mathrm{C}\right) ; \mathrm{H}_{2} \mathrm{SO}_{4}$ (95\%, Vetec), $\mathrm{Na}_{2} \mathrm{SO}_{4}$ (99\%, SigmaAldrich) and $\mathrm{D}_{2} \mathrm{O}$ (Sigma-Aldrich). The supporting electrolyte solution was as follows: $\mathrm{Na}_{2} \mathrm{SO}_{4} 0.45 \mathrm{~mol} \mathrm{~L}^{-1}$ at $\mathrm{pH} 1$, acidified with $\mathrm{H}_{2} \mathrm{SO}_{4}$. $\mathrm{D}_{2} \mathrm{O}$ content was set to $10 \%$ of the total solution volume.

\subsection{Apparatus}

Electrochemical measurements were performed with a EmStat2 potentiostat (Utrecht, The Netherlands). ${ }^{1} \mathrm{H}$ NMR experiments were carried out in a $600 \mathrm{MHz}$ NMR spectrometer (Ascend ${ }^{\mathrm{TM}} 600$ Bruker) at $25^{\circ} \mathrm{C}$, using $30^{\circ}$ pulses, 64 scans and a relaxation delay (d1) of $2 \mathrm{~s}$.

\subsection{Electrochemical-NMR cell}

The EC-NMR cell, in which all of the electrochemical experiments were performed, consisted of a three-electrode system inside a 14-cm-long, 5-mm NMR tube. Working electrode (WE) comprised of carbon fibers (CF) (each of the ca. 300 to 5000 fibers had $6.3 \mu \mathrm{m}$ in diameter and $2 \mathrm{~mm}$ in length) fixed in a glass capillary tube, as described in the literature [2]. Electrical contacts were made with conductive epoxy resin. Counter electrode (CE) consisted of a platinized Pt wire inside a glass capillary, whereas pseudo-RE comprised a silver wire coated with an $\mathrm{AgCl}$ film (Fig. 1). Electrochemical experiments were performed at $25{ }^{\circ} \mathrm{C}$, using a sample volume of $600 \mu \mathrm{L}$, the same electrical cable ( $3 \mathrm{~m}$ total length and $200 \mu \mathrm{H}$ chokes for each electrode) was used in in situ and ex situ experiments (scheme available in the supplementary material) and the cell was used in a vertical orientation.

\subsection{Diffusion measurements}

${ }^{1} \mathrm{H}$ DOSY measurements were carried out in duplicate, while the current was flowing, on a 14.1 T Ascend ${ }^{\text {TM}} 600$ Bruker spectrometer, which operates at $600.13 \mathrm{MHz}$ for ${ }^{1} \mathrm{H}$, equipped with a $5 \mathrm{~mm} \mathrm{BBO}$ probe, that produces a nominal maximum gradient of $50.1 \mathrm{G} \mathrm{cm}^{-1}$ in a z-gradient coil. The ${ }^{1} \mathrm{H}$ DOSY data were acquired using the ledbpgp2s Bruker's pulse sequence at $25^{\circ} \mathrm{C}$ with standard variable temperature regulation. Sixteen nominal gradient amplitudes were used ranging from 4.8 to $38.5 \mathrm{G} \mathrm{cm}^{-1}$, employing the diffusion time (d20) $90 \mathrm{~ms}$, the gradient recovery delay $(\delta) 0.2 \mathrm{~ms}$, the length of the diffusion gradient (p30) $0.7 \mathrm{~ms}$, and the additional longitudinal eddy current delay (d21) 5 ms. The diffusion coefficients values and the correlations map were obtained with the Bruker's Dynamics Center software.

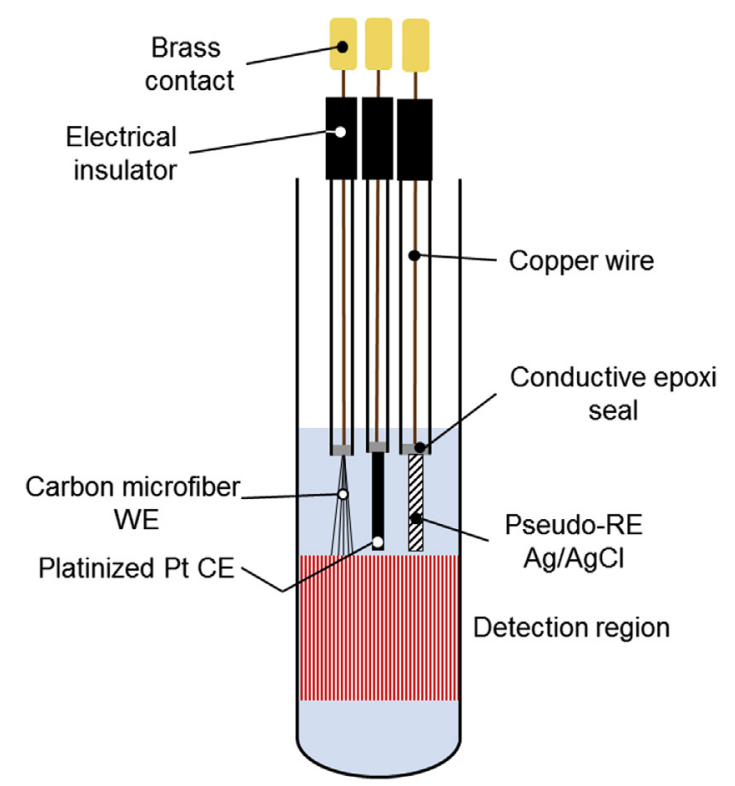

Fig. 1. Electrochemical cell illustration. The cell was built in a NMR tube of $5 \mathrm{~mm}$ diameter. The cell is not to scale. 


\subsection{Electrochemical measurements}

The electrochemical reaction behaviors inside and outside the magnetic field were studied using both cyclic voltammetry and chronoamperometry. Cyclic voltammetry measurements were obtained at potentials ranging from $-1 \mathrm{~V}$ to $+1 \mathrm{~V}$ ( $v s$. $\mathrm{Ag} / \mathrm{AgCl}$ pseudo$\mathrm{RE}$ ), using a scan rate of $100 \mathrm{mV} \mathrm{s}^{-1}$ and a step potential of $10 \mathrm{mV}$. Chronoamperometry data were acquired at a potential of $-600 \mathrm{mV}$ for $30 \mathrm{~min}$.

\subsection{Measurement definitions}

In situ electrochemical measurements were those performed inside the NMR spectrometer simultaneously with the NMR measurements. Temperature was maintained at $25{ }^{\circ} \mathrm{C}$.

Ex situ electrochemical measurements were performed under the same temperature conditions as in situ experiments $\left(25^{\circ} \mathrm{C}\right)$ but outside the NMR spectrometer. NMR measurements were performed before and after the electrochemical reactions. The electrodes and wires were not removed from the cell for the NMR measurements. The solution was well mixed before the NMR measurements.

\section{Results and discussion}

Fig. 2 presents the voltammograms of the electroredution of $p$ benzoquinone (BQ) in aqueous solution $\left(0.045 \mathrm{~mol} \mathrm{~L}^{-1}\right.$ in $\mathrm{Na}_{2} \mathrm{SO}_{4}$ $0.45 \mathrm{~mol} \mathrm{~L}^{-1}, \mathrm{pH}=1$ ) both in the presence and absence of a $14.1 \mathrm{~T}$ NMR magnetic field. This figure shows that $\mathbf{B}$ dramatically changed the voltammogram profile. When B was present, the cathodic current, $\mathbf{i}_{c},\left(\mathbf{i}_{c, 14 T}=-0.93 \mathrm{~mA}\right)$ was approximately four times greater than that in the absence of $\mathbf{B}\left(\mathbf{i}_{c, 0 T}=-0.23 \mathrm{~mA}\right)$ - both experiencing a $-600 \mathrm{mV}$ potential $(v s$. $\mathrm{Ag} / \mathrm{AgCl}$ pseudo reference electrode (pseudo-RE)). This effect may be explained by the action of $\mathbf{F}_{\mathbf{L}}$ on mass transport, which leads to an increased number of $\mathrm{BQ}$ molecules that reach the electrode surface, enhancing the reaction rate. Furthermore, the change on the voltammogram profile could be related to changes in the potential difference between the electrode and the solution or changes in the reaction mechanism [28].

The peak current, $\mathbf{i}_{a p}$, in the anodic branch (Fig. 2) in the presence of $\mathbf{B}\left(\mathbf{i}_{a p, 14 T}=0.33 \mathrm{~mA}\right)$ was lower than the B-free $\mathbf{i}_{a p}$ $\left(\mathbf{i}_{\text {ap }, 0 T}=0.85 \mathrm{~mA}\right)$, measured at 340 and $420 \mathrm{mV}$ (vs. $\mathrm{Ag} / \mathrm{AgCl}$ pseudo-RE), respectively. This may by attributed to the magnetic stirring caused by $\mathbf{F}_{\mathbf{L}}$, which might mix the solution and facilitate the transport of the reaction product (i.e., Hydroquinone (HQ)). Therefore, when the cyclic voltammetry swept towards anodic potentials, HQ had already diffused to the solution bulk, decreasing HQ concentration next to the electrode surface and, as a consequence, reducing $\mathbf{i}_{a p}$. Since the experiments were all performed at $25{ }^{\circ} \mathrm{C}$ we can safely say that the observed effect is due to the magnetic field and not due to temperature fluctuations.

Fig. 3 shows the chronoamperograms acquired in a single measurement both in the presence and absence of $\mathbf{B}$, aiming to demonstrate the instantaneous effect of $\mathbf{B}$ on the electrochemical reaction. As observed in Fig. 3, the current was intensified when the cell was placed in the magnetic field of the NMR spectrometer (red region) and returned to lower values when the cell was removed (grey region). The chronoamperogram current was found to be higher, in absolute value, when the cell was under the effect of $\mathbf{B}$ when compared with that observed in ex situ conditions. The current disturbance in the presence of $\mathbf{B}$ can be associated with the stirring caused by $\mathbf{F}_{\mathbf{L}}[20,22,33]$.

Fig. 4 presents the ${ }^{1} \mathrm{H}$ NMR spectra of the solution after $30 \mathrm{~min}$ of $(\mathrm{a})$ ex situ $(\mathrm{B}=0 \mathrm{~T})$ and $(\mathrm{b})$ in situ $(\mathrm{B}=14 \mathrm{~T})$ reactions as well as

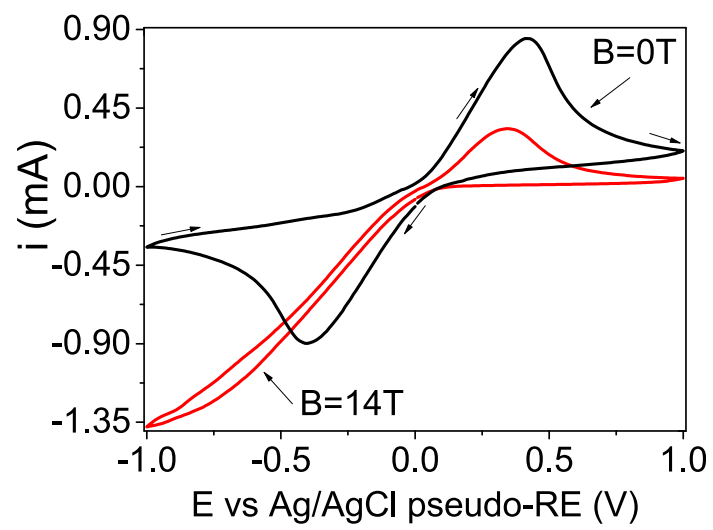

Fig. 2. Voltammograms acquired under ex situ (black line, $\mathrm{B}=0 \mathrm{~T}$ ) and in situ (red line, $\mathrm{B}=14 \mathrm{~T}$ ) conditions. Scan rate was $100 \mathrm{mV} \mathrm{s}^{-1}$ and number of cycles was 4 (scan number 4 is shown). A $550 \mu \mathrm{L}$ aliquot of a BQ solution $\left(0.045 \mathrm{~mol} \mathrm{~L}^{-1}\right.$ in $\mathrm{Na}_{2} \mathrm{SO}_{4}$ $0.45 \mathrm{~mol} \mathrm{~L}^{-1}, \mathrm{pH}=1$ ) was used. A carbon fiber electrode was used as the working electrode. (For interpretation of the references to colour in this figure legend, the reader is referred to the web version of this article.)

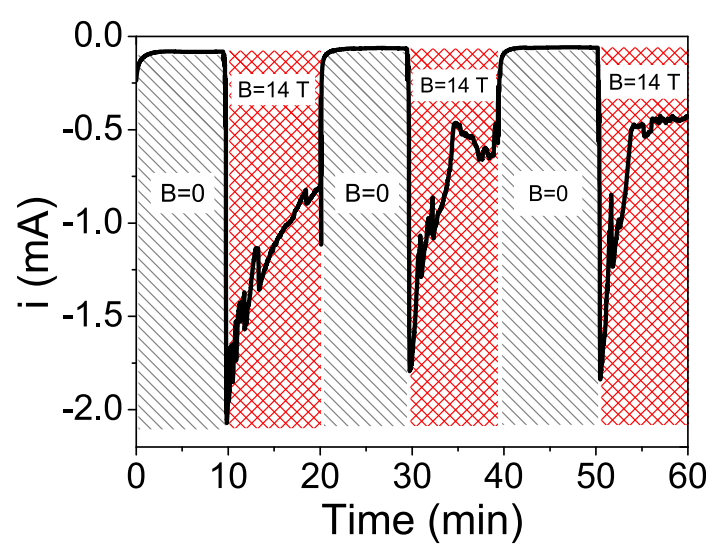

Fig. 3. Chronoamperogram performed both ex situ (grey region, $\mathrm{B}=0 \mathrm{~T}$ ) and in situ (red region, $\mathrm{B}=14 \mathrm{~T}$ ). Each of the tested conditions was maintained for $10 \mathrm{~min}$. The electrochemical cell (containing $550 \mu \mathrm{L}$ of a $0.045 \mathrm{~mol} \mathrm{~L}^{-1}$ BQ solution in $\mathrm{Na}_{2} \mathrm{SO}_{4}$ $0.45 \mathrm{~mol} \mathrm{~L}^{1}, \mathrm{pH}=1$ ) alternated between each condition six times. The applied potential was $-600 \mathrm{mV}$ (vs. $\mathrm{Ag} / \mathrm{AgCl}$ pseudo-RE). (For interpretation of the references to colour in this figure legend, the reader is referred to the web version of this article.)

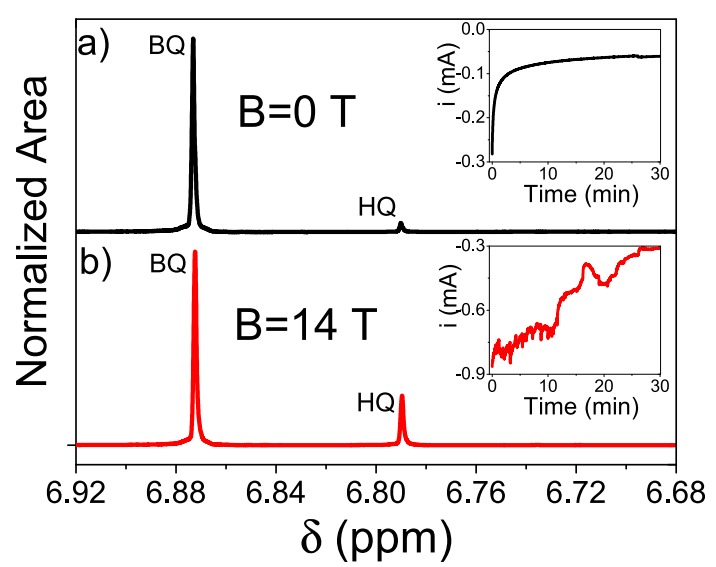

Fig. 4. NMR spectra acquired under the following ex situ (black line, $\mathrm{B}=0 \mathrm{~T}$ ) and in situ (red line, $\mathrm{B}=14 \mathrm{~T}$ ) conditions: $30^{\circ}$ pulse, 64 scans, relaxation delay (d1) of $2 \mathrm{~s}$ and $25{ }^{\circ} \mathrm{C}$. Spectra were recorded after chronoamperometric measurements (30 min, $-600 \mathrm{mV}$ (vs. $\mathrm{Ag} / \mathrm{AgCl}$ pseudo-RE), a) ex situ and b) in situ. (For interpretation of the references to colour in this figure legend, the reader is referred to the web version of this article.) 


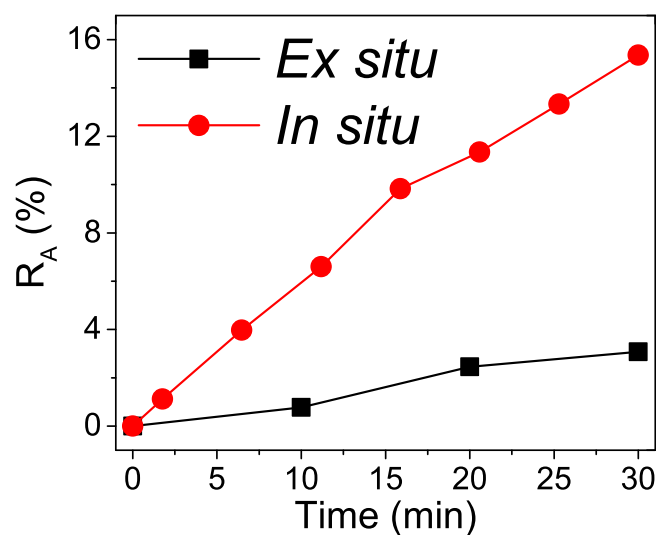

Fig. 5. $\left(R_{A}=\frac{A_{\mathrm{HQ}}}{A_{\mathrm{HQ}}+A_{\mathrm{BQ}}} \times 100 \%\right)$ ratios determined in ${ }^{1} \mathrm{H}$ NMR measurements vs. electrochemical reaction time for ex situ (black squares) and in situ (red circles) conditions. The electrochemical cell contained $550 \mu \mathrm{L}$ of a $0.045 \mathrm{~mol} \mathrm{~L}^{-1}$ BQ solution in $\mathrm{Na}_{2} \mathrm{SO}_{4}$ $0.45 \mathrm{~mol} \mathrm{~L}^{-1}, \mathrm{pH}=1$. Conditions: $-600 \mathrm{mV}$ ( $v s$. $\mathrm{Ag} / \mathrm{AgCl}$ pseudo-RE). (For interpretation of the references to colour in this figure legend, the reader is referred to the web version of this article.)

and the respective chronoamperograms (insets). The ratio of the areas $\left(R_{A}\right)$ of the NMR signals of $H Q\left(A_{H Q}\right)$ and $B Q\left(A_{B Q}\right)$, located at $6.79 \mathrm{ppm}$ and $6.87 \mathrm{ppm}$ respectively, $\left(R_{A}=\frac{A_{H Q}}{A_{\mathrm{HQ}}+A_{B Q}} \times 100 \%\right)$ was used to monitor the reduction reaction. Fig. 5 shows $R_{A}$ variation in ex situ and in situ reactions. After $30 \mathrm{~min}$ of reaction, $R_{A}$ was five times greater when the reaction was performed in situ (15\%) than when it was carried out ex situ (3\%). This enhancement is in the same order of magnitude as the increase in the chronoamperogram current. Ex situ NMR spectroscopy measurements were performed prior to electrolysis (at $-600 \mathrm{mV}$ (vs. $\mathrm{Ag} / \mathrm{AgCl}$ pseudo-RE)) as well as after 10, 20 and $30 \mathrm{~min}$. A brand new solution was used for each of these measurement times. In situ NMR measurements were performed at different times throughout the reaction. After the in situ reaction was performed two NMR measurements were made. One just after the reaction and one after mixing the solution, in order to evaluate if the reaction product was more concentrated in certain regions of the solution. We found no significant differences between these two measurements, which indicates that the reaction product is already well distributed in the solution.

We estimated that $\left|\mathbf{F}_{\mathbf{L}}\right|$ should have an intensity between 40 and $700 \mathrm{~N} \mathrm{~m}^{-3}$. For these calculations an average current of $-0.6 \mathrm{~mA}$ was considered, the number of carbon microfibers was considered to be between 300 and 5000 . The intensity of $\left|\mathbf{F}_{\mathbf{L}}\right|$ is in agreement with the results obtained by Ref. [34].

The stirring effect caused by $\mathbf{F}_{\mathbf{L}}$ on the whole sample was estimated using Diffusion Ordered NMR Spectroscopy (DOSY) [35]. The diffusion coefficient of water in the solution before the electrochemical reaction was determined to be $1.78 \pm 0.00 \times 10^{-9} \mathrm{~m}^{2} \mathrm{~s}^{-1}$. During the reaction, the mass transport (diffusion plus stirring) increased the apparent diffusion coefficient by $7 \%$ $\left(1.89 \pm 0.01 \times 10^{-9} \mathrm{~m}^{2} \mathrm{~s}^{-1}\right)$. This indicates that the turbulence caused by $\mathbf{F}_{\mathbf{L}}$ acts strongly in the vicinity of the electrodes, but also affects all the volume as confirmed by the chronoampetrometric and voltammetric measurements.

It is worth noting that we only reported the diffusion coefficients of water because the concentration of this compound does not suffer significant changes during the reaction. In the DOSY experiment the diffusion coefficient is measured based on the decrease of the signal area during the experiment due to only diffusion phenomena, therefore, the ideal condition for these measurements is that the signals retain the initial area. Nevertheless it was possible to determine the diffusion constant of $\mathrm{BQ}$ before, during and after the reaction and for HQ only after the reaction and these values are presented in the supplementary material. However, note that the error associated with these values is increased due to the variation of the concentration of these species during the reaction.

\section{Conclusion}

The rate of electrochemical reactions was enhanced when NMR measurements were performed in situ. This is also true for EPR and MRI, suggesting that these do not denote passive analytical methods, especially when the EC reaction is limited by mass transport or charge transfer.

Taking into account that all papers published until now, which used EC-NMR high resolution, did not consider the strong magnetic field effect on the electrochemical reactions performed in situ and its influence on the reaction kinetics or even on the reaction mechanism, it is imperative that this information is passed on to the scientific community that wishes to use the EC-NMR coupling.

Finally, whatever the geometry used for the experimental setup it is always necessary to evaluate the existence and intensity of the Lorentz force when the reaction is mass transport and/or charge transfer limited, as it can be present in the form of either the MHD and/or micro MHD effect.

\section{Acknowledgments}

The authors thank the Brazilian agencies FAPESP (Grant $\mathrm{N}^{o}$ 2012/22281-9), CAPES (Grant $\mathrm{N}^{o}$ 1646526) and CNPq (Grant $\mathrm{N}^{o}$ $161555 / 2015-2)$ for the financial support provided to this research.

\section{Appendix A. Supplementary data}

Supplementary data related to this article can be found at http:// dx.doi.org/10.1016/j.aca.2017.06.008.

\section{References}

[1] J.A. Richards, D.H. Evans, Flow cell for electrolysis within the probe of a nuclear magnetic resonance spectrometer, Anal. Chem. 47 (6) (1975) 964-966.

[2] S. Klod, F. Ziegs, L. Dunsch, In situ NMR spectroelectrochemistry of higher sensitivity by large scale electrodes, Anal. Chem. 81 (24) (2009) 10262-10267, http://dx.doi.org/10.1021/ac901641m. URL $<$ Go to Isi $>$ ://wos: 000272562200054.

[3] S. Klod, K. Haubner, E. Jaehne, L. Dunsch, Charge stabilisation by dimer formation of an endcapped thiophene tetramer-an in situ NMR spectroelectrochemical study, Chem. Sci. 1 (6) (2010) 743-750, http://dx.doi.org/ 10.1039/c0sc00350f. URL < Go to Isi>://wos:000283939200012.

[4] S. Klod, L. Dunsch, A combination of in situ ESR and in situ NMR spectroelectrochemistry for mechanistic studies of electrode reactions: the case of p-benzoquinone, Magn. Reson. Chem. 49 (11) (2011) 725-729, http:// dx.doi.org/10.1002/mrc.2819. URL <Go to Isi>://wos:000296609600007.

[5] R.D. Webster, In situ electrochemical-NMR spectroscopy. Reduction of aromatic halides, Anal. Chem. 76 (6) (2004) 1603-1610, http://dx.doi.org/ 10.1021/ac0351724. URL <Go to Isi>://wos:000220225200008.

[6] U. Bussy, M. Boujtita, Review of advances in coupling electrochemistry and liquid state NMR, Talanta 136 (2015) 155-160, http://dx.doi.org/10.1016/ j.talanta.2014.08.033. URL <Go to Isi>://wos:000350834700021.

[7] L.M.S. Nunes, T.B. Moraes, L.L. Barbosa, L.H. Mazo, L.A. Colnago, Monitoring electrochemical reactions in situ using steady-state free precession ${ }^{13} \mathrm{C}$ NMR spectroscopy, Anal. Chim. Acta 850 (2014) 1-5, http://dx.doi.org/10.1016/ j.aca.2014.05.022. URL < Go to Isi>://wos:000344210100001.

[8] D.F. Evans, The determination of the paramagnetic susceptibility of substances in solution by nuclear magnetic resonance, J. Am. Chem. Soc. (Jun) (1959) 2003-2005, http://dx.doi.org/10.1039/jr9590002003. URL <Go to Isi >://wos: a1959wk68700017.

[9] P.D. Prenzler, R. Bramley, S.R. Downing, G.A. Heath, High-field NMR spectroelectrochemistry of spinning solutions: simultaneous in situ detection of electrogenerated species in a standard probe under potentiostatic control, Electrochem. Commun. 2 (7) (2000) 516-521, http://dx.doi.org/10.1016 s1388-2481(00)00042-4. URL <Go to Isi>://wos:000087976000014.

[10] D.W. Mincey, M.J. Popovich, P.J. Faustino, M.M. Hurst, J.A. Caruso, Monitoring of electrochemical reactions by nuclear-magnetic-resonance spectrometry, 
Anal. Chem. 62 (11) (1990) 1197-1200, http://dx.doi.org/10.1021/ ac00210a020. URL < Go to Isi >://wos:a1990de94100021.

[11] U. Bussy, P. Giraudeau, I. Tea, M. Boujtita, Understanding the degradation of electrochemically-generated reactive drug metabolites by quantitative NMR Talanta 116 (2013) 554-558, http://dx.doi.org/10.1016/j.talanta.2013.07.026. URL $<$ Go to Isi>://wos:000328176000081.

[12] R. Bhattacharyya, B. Key, H. Chen, A.S. Best, A.F. Hollenkamp, C.P. Grey, In situ NMR observation of the formation of metallic lithium microstructures in lithium batteries, Nat. Mater. 9 (6) (2010) 504-510, http://dx.doi.org/10.1038 nmat2764. URL < Go to Isi>://wos:000277926600018.

[13] N.M. Trease, T.K.J. Köster, C.P. Grey, In situ NMR studies of lithium ion batteries, J. Electrochem. Soc. Interface 20 (3) (2011) 69-73.

[14] N.M. Trease, L.N. Zhou, H.J. Chang, B.Y.X. Zhu, C.P. Grey, In situ NMR of lithium ion batteries: bulk susceptibility effects and practical considerations, Solid State Nucl. Magn. Reson. 42 (2012) 62-70, http://dx.doi.org/10.1016/ j.ssnmr.2012.01.004. URL <Go to Isi >://wos:000302493200009.

[15] P. Rapta, O. Zeika, D. Rohde, H. Hartmann, L. Dunsch, Thiophene-thiophene versus phenyl-phenyl coupling in 2-(diphenylamino)-thiophenes: an ERS-UV/ VIS/NIR spectroelectrochemical study, Chemphyschem 7 (4) (2006) 863-870, http://dx.doi.org/10.1002/cphc.200500533. URL <Go to Isi >://wos: 000236838000016

[16] M. Klett, M. Giesecke, A. Nyman, F. Hallberg, R.W. Lindström, G. Lindbergh I. Furó, Quantifying mass transport during polarization in a $\mathrm{Li}$ ion battery electrolyte by in situ 7 Li NMR imaging, J. Am. Chem. Soc. 134 (36) (2012) 14654-14657, http://dx.doi.org/10.1021/ja305461j.

[17] P.P.R.M.L. Harks, F.M. Mulder, P.H.L. Notten, In situ methods for Li-Ion battery research: a review of recent developments, J. Power Sources 288 (2015) 92-105, http://dx.doi.org/10.1016/j.jpowsour.2015.04.084.

[18] S.A. Krachkovskiy, J.D. Bazak, P. Werhun, B.J. Balcom, I.C. Halalay, G.R. Goward Visualization of steady-state ionic concentration profiles formed in electrolytes during Li-Ion battery operation and determination of mass-transport properties by in situ magnetic resonance imaging, J. Am. Chem. Soc. 138 (25) (2016) 7992-7999, http://dx.doi.org/10.1021/jacs.6b04226.

[19] S. Cao, Z. Ni, L. Huang, H. Sun, B. Tang, L. Lin, Y. Huang, Z. Zhou, S. Sun, Z. Chen, In situ monitoring potential-dependent electrochemical process by liquid NMR spectroelectrochemical determination: a proof-of-concept study, Anal. Chem. 0 (0) (0) null.http://dx.doi.org/10.1021/acs.analchem.7b00249.

[20] L.M.A. Monzon, L. Klodt, J.M.D. Coey, Nucleation and electrochemical growth of zinc crystals on polyaniline films, J. Phys. Chem. C 116 (34) (2012) 18308-18317, http://dx.doi.org/10.1021/jp306071c. URL <Go to Isi>://wos: 000308120000039 .

[21] L.M.A. Monzon, J.M.D. Coey, Magnetic fields in electrochemistry: the kelvin force. a mini-review, Electrochem. Commun. 42 (2014) 42-45, http:// dx.doi.org/10.1016/j.elecom.2014.02.005. URL <Go to Isi >://wos: 000335705500011

[22] L.M.A. Monzon, J.M.D. Coey, Magnetic fields in electrochemistry: the lorentz force. a mini-review, Electrochem. Commun. 42 (2014) 38-41, http:// dx.doi.org/10.1016/j.elecom.2014.02.006. URL <Go to Isi >://wos:
000335705500010

[23] A. Bund, S. Koehler, H.H. Kuehnlein, W. Plieth, Magnetic field effects in electrochemical reactions, Electrochim. Acta 49 (1) (2003) 147-152, http:// dx.doi.org/10.1016/j.electacta.2003.04.009. URL $<$ Go to Isi $>$ ://wos: 000187179700015

[24] A. Bund, H.H. Kuehnlein, Role of magnetic forces in electrochemical reactions at microstructures, J. Phys. Chem. B 109 (42) (2005) 19845-19850, http:// dx.doi.org/10.1021/jp053341d. URL <Go to Isi>://wos:000232857900041.

[25] G. Hinds, F.E. Spada, J.M.D. Coey, T.R.N. Mhiochain, M.E.G. Lyons, Magnetic field effects on copper electrolysis, J. Phys. Chem. B 105 (39) (2001) 9487-9502, http://dx.doi.org/10.1021/jp010581u. URL <Go to Isi>://wos: 000171400800014

[26] C. O'reilly, G. Hinds, J.M.D. Coey, Effect of a magnetic field on electrodeposition - chronoamperometry of $\mathrm{Ag}, \mathrm{Cu}, \mathrm{Zn}$ and $\mathrm{Bi}, \mathrm{J}$. Electrochem. Soc. 148 (10) (2001) C674-C678, http://dx.doi.org/10.1149/1.1402121. URL <Go to Isi>:// wos:000171501600034

[27] N. Leventis, A. Dass, Demonstration of the elusive concentration-gradient paramagnetic force, J. Am. Chem. Soc. 127 (14) (2005) 4988-4989.

[28] E.J. Kelly, Magnetic-field effects on electrochemical reactions occurring at metal-flowing-electrolyte interfaces, J. Electrochem. Soc. 124 (7) (1977) 987-994, http://dx.doi.org/10.1149/1.2133514.

[29] B.F. Gomes, L.M.S. Nunes, C.M.S. Lobo, L.F. Cabeça, L.A. Colnago, In situ study of the magnetoelectrolysis phenomenon during copper electrodeposition using time domain NMR relaxometry, Anal. Chem. 86 (19) (2014) 9391-9393, http://dx.doi.org/10.1021/ac502361q.

[30] B.F. Gomes, L.M.S. Nunes, C.M.S. Lobo, A.S. Carvalho, L.F. Cabeça, L.A. Colnago, In situ analysis of copper electrodeposition reaction using unilateral NMR sensor, J. Magn. Reson. 261 (2015) 83-86, http://dx.doi.org/10.1016/ j.jmr.2015.09.018.

[31] X. Zhang, J.W. Zwanziger, Design and applications of an in situ electrochemical NMR cell, J. Magn. Reson. 208 (1) (2011) 136-147, http://dx.doi.org/10.1016/ j.jmr.2010.10.013. URL <Go to Isi>://wos:000286774300017.

[32] W. Lohmann, U. Karst, Simulation of the detoxification of paracetamol using on-line electrochemistry/liquid chromatography/mass spectrometry, Anal. Bioanal. Chem. 386 (6) (2006) 1701-1708, http://dx.doi.org/10.1007/s00216006-0801-Y.

[33] O. Aaboubi, J. Douglade, Application of magnetic field to control mass transport process during silver cementation on copper, J. Electroanal. Chem. 693 (2009) 42-50, http://dx.doi.org/10.1016/j.electacta.2009.05.036. URL < Go to Isi >://wos:000268374900031.

[34] S.R. Ragsdale, K.M. Grant, H.S. White, Electrochemically generated magnetic forces. enhanced transport of a paramagnetic redox species in large, nonuniform magnetic fields, J. Am. Chem. Soc. 120 (51) (1998) 13461-13468, http://dx.doi.org/10.1021/ja982540q. URL <Go to Isi $>$ ://wos: 000077874300024

[35] J.A. Aguilar, R.W. Adams, M. Nilsson, G.A. Morris, Suppressing exchange effects in diffusion-ordered NMR spectroscopy, J. Magn. Reson. 238 (2014) 16-19, http://dx.doi.org/10.1016/j.jmr.2013.10.018. 